\title{
Profiling and understanding student information behaviour: methodologies and meaning
}

\author{
Jennifer Rowley \\ Edge Hill College of Higher Education, UK \\ email: rowleyj@edgehill.ac.uk
}

This paper draws on work conducted under the Joint Information Systems Committee (JISC) User Behaviour Monitoring and Evaluation Framework to identify a range of issues associated with research design that can form a platform for enquiry about knowledge creation in the arena of user behaviour. The Framework has developed a multidimensional set of tools for profiling, monitoring and evaluating user behaviour. The Framework has two main approaches: one, a broad-based survey which generates both a qualitative and a quantitative profile of user behaviour, and the other a longitudinal qualitative study of user behaviour that (in addition to providing in-depth insights) is the basis for the development of the EIS (Electronic Information Services) Diagnostic Toolkit. The strengths and weaknesses of the Framework approach are evaluated. In the context of profiling user behaviour, key methodological concerns relate to: representativeness, sampling and access, the selection of appropriate measures and the interpretation of those measures. Qualitative approaches are used to generate detailed insights. These include detailed narratives, case study analysis and gap analysis. The messages from this qualitative analysis do not lend themselves to simple summarization. One approach that has been employed to capture and interpret these messages is the development of the EIS Diagnostic Toolkit. This toolkit can be used to assess and monitor an institution's progress with embedding EIS into learning processes. Finally, consideration must be given to integration of insights generated through different strands within the Framework.

\section{Introduction}

The interaction between students and electronic resources in support of the learning process is important for all agencies involved in the learning process, including lecturers, libraries and learners.

User behaviour in networked environments has been explored for a number of different purposes and from different disciplinary bases. Both commercial and public sector 
organizations are interested in user response to Web environments, and user, consumer, employee and learner behaviour has attracted and continues to attract considerable interest. The purposes for which investigation into user behaviour in Web-based environments has been pursued include:

- Profiling user behaviour - in this context it is necessary to understand the key parameters that define an appropriate and useful profile, or to think about those aspects of behaviour that it makes sense to measure (for example, Agarwal and Prasad, 1997; Australian Bureau of Statistics, 1999; Chau, 2000; Graphic Visualisation and Usability Center, 1999-; Griffith, Ashworth, Ward and Marsden, 1999; Lin and Lu, 2000).

- Pursuit of enhancements in service delivery. Service delivery is often evaluated in terms of the match between the service user's expectation and perceptions of the service experience or episode. In order to enhance service delivery it is typically necessary to manage both operational details and user expectations (for example, Bobbitt and Dabholker, 2001; Dalgleish and Hall, 2000; De Ruyter, Wetzels and Kleijnen, 2001; Novak, Hoffman and Yung, 2000; Zeithaml, Parasuraman and Malhotra, 2000; Rust and Lemon, 2001).

- Performance measurement, in pursuit of understanding whether the tools available for learning are fit for the purpose for which they are intended. This requires a definition of the purpose of the tools, and the selection of performance indicators and performance measures that reflect the key purpose (for example, Clarke, 1999; IMPEL2, 2001; Saracevic and Kantor, 1997)

- Monitoring trends and change, perhaps to note the effect of the injection of additional resources and facilities, or alternatively to justify or assess the need for continued injection of resources; such resources might include technology or training (for example, Detlor, 1999; Lubans, 2000).

- To inform the design of electronic information environments, both in relation to usability and Website design, but also in the evaluation of specific projects or tools to provide access to information resources, such as those under the eLib or JISC Distributed National Electronic Resource (DNER) funded initiatives (for example, Battleson, Booth and Weinthrop, 2001; Davies, 1998; Kucuk and Arslan, 2000; Mackie and Burton, 1999; Ozok and Salvendy, 2000; Rettie, 2001; AGORA, 2000; EDNER, 2001).

- To develop an enhanced theoretical understanding of learning in electronic information environments in order to support policy initiatives concerning learning (for example, Bawden, 2001; Davies and Cohen, 2001 as summarized by Brophy, 2001; Eskola, 1999; Heinstrom, 2000; SCONUL, 1999).

One of the very real problems in developing a theoretical understanding of user behaviour is drawing together the outcomes from numerous, often small-scale studies conducted with different groups, asking different questions for different purposes, and emerging from different disciplinary traditions. It is important to seek to understand the relationships between these studies performed for different purposes and within different contexts. This article takes a step in this direction by using the opportunity afforded by the large-scale and multidimensional JISC User Behaviour Monitoring and Evaluation Framework to 
explore some of the common methodological considerations that influence understanding of user behaviour. Aspects of the Framework are explained as a basis for comment on wider-ranging methodological issues. It is not, however, the purpose of this study to report in detail on either the methodology or the findings of the Framework. For those interested in this perspective a range of reports on the Framework are available through the JISC Assist Website (www.jisc.assist.ac.uk) and the articles that have emerged from the Framework (such as Armstrong et al., 2001, 2002; Banwell and Gannon Leary, 2000, 2001; Rowley, 2001a, 2001b).

In 1999, JISC responded to the need to profile, monitor and evaluate user behaviour by establishing the User Behaviour Monitoring and Evaluation Framework. The Framework specifically focuses on the development of a longitudinal profile of the use of electronic information services and the development of an understanding of the triggers and barriers that affect such use. The monitoring activities within the Framework take place on an annual cycle, initially supported for three years. The two strands that relate to user behaviour are Strands $A$ and $D$. Strand $A$ is an annual survey that seeks to measure and evaluate the overall awareness, uptake, usage and usefulness of information technologies and information services in higher education in the United Kingdom. The survey was conducted by critical incident-based interviews, e-mail and paper-based questionnaires, and is part of the JUSTEIS project at the University of Aberystwyth. Strand D is a linked programme of ongoing, longitudinal monitoring of the information behaviour, needs and opportunities for specific academic and student communities, and for academics and students in general. The study has been conducted through the JUBILEE project at the University of Northumbria. The Framework has been co-ordinated by the JISC Scientific Adviser. One of the strengths of this strand-based approach is that the mixed qualitative and quantitative methodology generates a rich picture and a set of deliverables that have the potential to address the perspectives of, and to be of value to, a variety of different audiences. This paper draws upon the work within the Framework to reflect upon methodological issues associated with understanding user, and more specifically student, information behaviour. In undertaking this reflective critique of our work, we reveal the complexity associated with understanding user behaviour.

The article starts with a review of the research design for the Framework. The core of the paper explores a range of methodological issues that arise from the two main projects, JUSTEIS and JUBILEE. Finally, the issue of integration is discussed. Using the perspective of this major project, the article raises a range of issues associated with research design that can form a platform for enhanced knowledge creation and understanding in the arena of user behaviour.

\section{Research design}

The underlying philosophy that determined the overall design of the Framework embraced several of the lenses that could be applied to understand user behaviour. This multipleperspective approach involved some inherent contradictions. For example, Strand D seeks to identify the factors that influenced user behaviour through a grounded theory approach based on semi-structured interviews and other contexts in which users were encouraged to describe and analyse their attitudes and behaviour. Yet in parallel, and therefore in the absence of summative insights from Strand D, Strand A needed to design a general survey 
on the use of EIS. This general survey needed to identify questions for inclusion in both questionnaires and interviews.

Whilst Strand A was focused on the delivery of a profile, and Strand D on an understanding of user behaviour, ultimately the strands share many questions. Key questions for both strands are:

- Which EIS do users use?

- How do they use EIS?

- What do they use EIS for?

- What influences their use of EIS?

- Are differences in the use of EIS discernible between different groups?

- Is the use of EIS changing, and what will be the impact of that change on learning processes?

With shared questions at the foundation of both projects there is scope for overlap and conflict in relation to the contexts of the fieldwork, the design of the data collection instruments, the conceptual frameworks and the project outcomes. This potential basis for conflict and duplication needs to be converted into creative synergy.

A particularly valuable but challenging aspect of the, Framework is the requirement to generate longitudinal data about the changes in user behaviour. This involves the identification of 'measures' that can be reassessed on an annual basis. It also implies a commitment to the design of an approach that has a life beyond the current funding and contractual arrangements associated with the research. Ideally, such work needs to have a ten-year time frame but sustaining such a programme presents all sorts of financial, operational and logistical dilemmas. However, without such a commitment all that can be achieved is a series of loosely linked snapshots of user behaviour on the basis of which it is difficult to generalize and to develop a sufficiently rich picture to inform both practice and policy-making.

The Framework also needs to evolve as factors in the environment change. Changes can be anticipated in policy agendas affecting the composition of the student community and priorities in relation to elements of and the nature of the student experience, technological innovation, and the range of EIS that are available to users.

The design of the Framework as a set of separate projects, overviewed and coordinated (but not administered or managed) by a third party, has a number of strengths and some challenges. These are of interest because they are likely to be experienced by other large projects on user behaviour. Any overarching project management structure impacts on the outcomes of the project, and is relevant to the methodology for the Framework as a whole. The strengths and challenges are summarized below.

\section{Strengths}

1. The mixed qualitative and quantitative methodology generates a rich picture and a set of deliverables that have the potential to address the perspectives of, and to be of value to, a variety of different audiences. 
Jennifer Rowley Profiling and understanding student information behaviour: methodologies and meaning

2. The approach draws on many project team members, with diverse competencies, disciplinary allegiances, methodological perspectives, views of priorities and networks. This presents a rich resource, which has the potential to be extremely creative.

3. Project teams learn from identification with a larger team; knowledge and insights can be created through the virtual team, and valuable research networks are strengthened.

4. The work of any one project team comes under close scrutiny from another project team that is working on a parallel project; thus research is submitted to critical formative evaluation.

\section{Challenges}

1. Identification of the most effective approaches to integration, and the interleaving of integration with work on projects, taking into account that the project teams have been specifically funded by JISC to complete their specific projects.

2. Managing integration at an operational level, in relation to issues such as sampling and the design of data collection instruments.

3. Managing integration at a strategic level, in terms of creating ownership of a continuing review of what has been achieved overall and the extent to which this matches the original objectives of the Framework, whilst accommodating changes in the sector that might impact on those objectives.

4. The difficulties associated with bringing the project teams together on a reasonably regular basis, when they are both busy.

\section{Profiling user behaviour}

The questionnaires and interview schedules developed under JUSTEIS have been used in both further and higher education amongst a range of different categories of users. They are a useful resource for universities wishing to profile user behaviour. Such questionnaires and interview schedules can generate a descriptive profile of user behaviour amongst a user community. They, for example, provide answers to questions such as whether postgraduate students make use of JISC services or the purpose for which students are making use of EIS.

If data is collected at annual or biannual intervals they can be used to profile trends and changes in behaviour. Such changes may offer a perspective on the effects of enhanced or changed information services or the design of learning experiences on EIS use. For example, the results of the First Cycle revealed that 'search engines', 'e-mail', 'OPAC (Own institution)' and 'Local EIS' were the top four services used by students. In Second Cycle results, 'Search engines' and 'e-mail' remained in top position, but 'other Web EIS' and 'Own HEI Website' had replaced 'OPAC (Own institution)' and 'Local EIS' in top position.

Similarly, if data is collected from different groups it is possible to profile behaviour specifically in relation to disciplines or different categories of students (such as. undergraduate Years 1, 2, 3 and postgraduate). It is, for instance, evident that patterns of use of EIS vary between disciplines, with the Pure and Applied Sciences cluster making noticeably more use of JISC-negotiated services than other disciplinary clusters and the 
Pure and Applied Social Sciences cluster making comparatively more use of organizational Websites.

There are, however, a number of dilemmas associated with a broad-based survey. These are perhaps more acute in a sector-wide survey than might be the case for a survey within an institution or studying a specific, more narrowly defined, group of users, but they apply for all such surveys, and are therefore important in understanding, interpreting and utilizing data. In the interests of simplification, the discussion here tends to take something of a quantitative bent. These issues are also significant in research that is pursuing answers to 'why' and 'how' questions. Issues for consideration include: representativeness, sampling and access; the selection of appropriate measures; and interpreting data.

\section{Representativeness, sampling and access}

Good surveys include responses from a randomly selected, or at the least an unbiased, sample of the population. The first challenge is to decide how the sample should be constituted. The JUSTEIS sampling methodology illustrates the potential for complexity in this process. First a sample of institutions was taken in order to ensure that a range of institutional types was included. A two-way categorization of higher education institutions (HEIs) was used, based on size of HEI in terms of undergraduate student numbers and institutional type. The next level of analysis used the multi-stage cluster sampling approach to provide a range of departments, evenly split amongst disciplinary clusters. This process should have led to the selection of fifty departments. Continuing with this level of rigour, the team initially sought lists of student e-mail addresses, from which they could select students on a random quota basis to ensure representation of different groups of students.

This rigorous approach proved unsatisfactory on at least two levels:

- Some departments selected could not participate, often due to faculty or departmental restructuring.

- Many departments did not have lists of students' e-mail addresses. Where these were held centrally, different sections of the university were responsible for them in different institutions, and access by appropriate agencies proved problematic. Data protection was also raised as an issue by some institutions. Finally, even when researchers managed to gather e-mail addresses, response rates from e-mails were poor.

Adjustments were made to the list of departments selected. Response rates from students were enhanced by making contact with key informants in departments, and through them academic staff, who then facilitated access to groups of students.

Accordingly, although the group of users engaging in the survey remained relatively large and spread across numerous departments, it became 'lumpy' with stronger representation from some institutions, departments and disciplinary clusters. Although the JUBILEE sampling was more focused because representativeness was not intended to derive from a broad-based sample, difficulty in accessing students again had the result of generating unevenness in the data collected. Access and participation issues eroded the theoretical sampling procedures. Limited and uneven response rate is always likely to be a limitation of such surveys and this needs to be acknowledged in the interrogation and intelligent use of survey data. 
Jennifer Rowley Profiling and understanding student information behaviour: methodologies and meaning

\section{Selection of appropriate measures}

How can user behaviour be measured? What are the performance indicators of appropriate user behaviour? The JUSTEIS project posed these questions in terms of:

- the purposes for which users used EIS;

- the types of EIS used;

- influences on student use of EIS; and

- student information skills education and training.

Data in response to the first two questions had the potential to be analysed according to the category of user (undergraduate, postgraduate, academic and research staff, and library and information services staff), and according to disciplinary group. Major reporting was chosen to be by category of user since this appeared to create the most significant differentials between the behaviour of the different groups. Comparison across years has been largely in terms of these categories. This has made it possible to appreciate the main purposes for which EIS are used: for assignment or lab report, or for background reading for personal research. These uses are common to both undergraduates and postgraduates, but postgraduates make greater use of a range of specialized and often discipline-specific EIS. Purposes for which staff use EIS are more diverse, but top of the list is student administration, followed by bibliography or reference checking, and planning leisure activity.

All questions required the development of specific sub-categories, such as the types of purposes and the types of EIS used. Different categories might have generated different insights. For example, the team needed to decide whether e-mail and OPACs were relevant EIS and what constituted relevant purposes within the remit of the study.

One important factor was the terms that were used to describe EIS categories to respondents: much of the terminology that the researcher might find useful for analysis is meaningless to many users. Although, for example, the project sponsors (JISC) were interested to know whether users were using a JISC-negotiated service, the average user would be totally unaware of the provenance or licensing arrangements associated with specific services. Accordingly free form responses were analysed using the EIS taxonomy developed for the purpose. All such taxonomies can be contested and whichever taxonomy is adopted, researchers need to perform post hoc categorization of users' responses during data analysis.

Another choice that had to be made related to reporting of use. The JUSTEIS team decided not to ask users to rank or rate frequency of use, but rather to provide information in relation to a recent 'critical incident of information use' and to identify the 'critical success factors'. The critical incident technique encourages respondents to tell the story of the information-seeking incident in their own terms, and can be used to explore the antecedents, the purposes of the search, the processes involved and outcomes (Urquhart, forthcoming). The critical success factors technique is useful in determining the individual's priorities and the contribution that information can make in the context of those priorities.

\section{Interpreting data}

Analysis and interpretation of the data collected depends upon survey objectives. A specific focus might, for example, be to monitor the relative use of EIS between first-year 
and second year undergraduates. Another study might be interested in the relative use of academic gateways and search engines. At the generic level at which the Framework has operated, the most pressing questions in relation to interpretation are of the type:

- What is the significance of the fact that 46.9 per cent of undergraduate students cited assignment or lab report as a purpose for using EIS, whereas only 9.8 per cent cited it for seminars or class presentation, only 6.5 per cent for dissertation or thesis and 6.8 per cent for online shopping?

- What are the implications of a rank ordering of types of EIS used by undergraduates which, for example, shows search engines (68.5 per cent) at the top of the list, with email (63.8 per cent) a close-run second, and JISC-negotiated services ( 8.5 per cent) as the least cited?

Underlying any interpretation is the matter of benchmarking - what would be a reasonable level of citation of specific sources? Should students undertaking different courses differ in the extent and nature of the use that they make of the different types of EIS? Benchmarking demands refinement of expectations regarding user information behaviour.

\section{Understanding and changing user behaviour}

Both JUSTEIS and JUBILEE have qualitative dimensions. For JUSTEIS, interviews provided richer data than questionnaires. Interviews are key to understanding behaviour and act as a means of identifying the early emergence of changes, such as the rapid emergence of Google as a 'universal' search tool for students, or the use of Web text messaging services.

In JUBILEE, rich interview and focus group data has been used to generate and inform:

- detailed narratives, in the respondents' own words, of EIS user behaviour;

- case study analysis of the use of EIS at the different sites;

- the gap analysis that exposes and explains gaps that exist between the expectations of user behaviour held by different groups; and

- the EIS Diagnostic Toolkit, which can be used on an institutional or disciplinary basis to monitor progress with the engagement of EIS.

One of the real challenges of the qualitative approach is to lift from a morass of anecdotal evidence some insights, tools and models that are useful to academics, managers and library and information professionals who need to work together to formulate and promote learning experiences that prepare students for continued learning in a digital environment. JUBILEE has sought to generate and analyse rich data in such a way that promotes understanding of user behaviour, as well as to create tools that can be used as the basis for management agendas for change and the monitoring and evaluating of change. Over the three cycles of the Framework, work has progressed towards the development of the EIS Diagnostic Toolkit. The Toolkit is a benchmarking tool that provides an action plan for HE managers to support them in the development of engagement with EIS at both at individual and institutional levels. The Toolkit is based on the characterization of user-based success criteria in relation to EIS. Evidence from Cycle 1 was used to identify 
the prerequisites for individual success in information-searching, and these have been used to generate the seven themes. The themes are:

- access to information;

- resource base;

- user skills;

- EIS and course design and delivery;

- EIS and student learning;

- quality assurance; and

- seamlessness (of access to EIS).

These themes have been developed in subsequent cycles, and form the basis of the structure for the toolkit. At the conclusion of Cycle 1, three example matrices were generated that illustrated how the themes can be used to profile disciplines:

- A matrix for one discipline (Business Studies) at six sites, showing the variations between sites in that discipline.

- Evidence of the three Cycle 1 target disciplines at one site, showing the variations between disciplines at the same site.

- Drilling down into one theme, showing Cycle 1 evidence of poor, intermediate and good practice from all sites.

In addition, as in subsequent cycles, the themes were used to summarize and characterize the qualitative evidence captured from the JUBILEE sites, and also to draft profiles of the case study sites.

During Cycle 2, taking work conducted by the research team at Northumbria for UKOLN (http://www.ukoln.ac.uk/services/elib/papers/supporting) as a departure point, a model of generic development stages was developed. These stages are summarized in Table 1. During Cycles 2 and 3 evidence has been presented of each of the different stages of

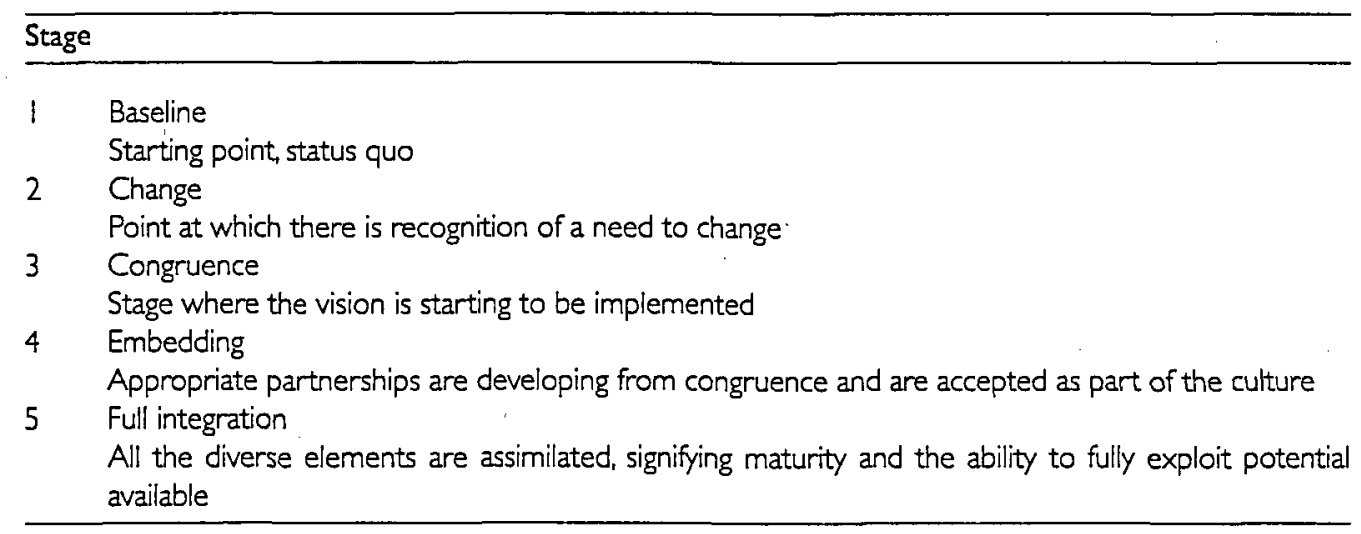

Table I: EIS Diagnostic Toolkit - generic development stoges 
development in the use of EIS. The final form of the toolkit manual will be multi-layered. The generic form of the toolkit will overlay the characterization of situations in different disciplines and sites. This form of presentation will permit institutions to tailor the illuminative material contained in it to their own situations, at institution, discipline or individual levels.

\section{Integration}

The original conceptualization of the Framework was as a series of interlinked strands. The mechanism for integration of these strands, and indeed the more general methodological issue of how the picture generated by qualitative and quantitative approaches might be integrated to produce a holistic picture, was left undefined. In addition, it is an extremely challenging task to use the data collection methodologies within the Framework in such a way as to generate insights or tools that might support each of the potential groups of stakeholders as they seek to develop their particular contribution to the advancement of a digital learning environment and community.

Integration within the Framework has developed through the three cycles of the Framework. This process is proposed as one approach to the integration of perspectives on user behaviour derived from different methodological bases. In Cycle 1, the primary focus was on project data collection and access methods. This generated frameworks for understanding, organizing and interpreting data at a project level. In Cycle 1 the Framework was a loosely-linked set of projects within an overarching set of objectives. During Cycle 2 the data collection approaches were tested and refined and further data was collected to populate data sets. In terms of integration, with the project methodologies reasonably established and stable, and a strong understanding of the type of issues that affect EIS, project teams had a stronger platform from which to understand the relationship between the separate projects. Cycle 3 provided a further opportunity to populate data sets, culminating in a cohesive set of deliverables (Table 2).

\begin{tabular}{|c|c|c|}
\hline Cycle & Key Activities & Level of Integration \\
\hline 1 & $\begin{array}{l}\text { Design and testing of project data collection } \\
\text { and access methodologies, leading to the } \\
\text { generation of frameworks for understanding } \\
\text { the data at project level. }\end{array}$ & $\begin{array}{l}\text { Loosely linked set of projects with an overarching } \\
\text { set of objectives. }\end{array}$ \\
\hline 2 & $\begin{array}{l}\text { Further refinement of data collection and } \\
\text { access methodologies. Further population of } \\
\text { data sets. }\end{array}$ & $\begin{array}{l}\text { Partial integration based on enhanced } \\
\text { understanding of the relationships between projects. }\end{array}$ \\
\hline 3 & $\begin{array}{l}\text { Further population of data sets. Refinement } \\
\text { of project data collection, and analysis to } \\
\text { generate a holistic picture of user behaviour. }\end{array}$ & $\begin{array}{l}\text { Full integration, evidenced through a holistic set of } \\
\text { deliverables. }\end{array}$ \\
\hline
\end{tabular}

Table 2: Phases of integration in framework methodology

\section{Conclusion}

The User Behaviour Monitoring and Evaluation Framework is an ambitious attempt to provide a methodology for creating multidimensional insights into the nature of user 
Jennifer Rowley Profiling and understanding student information behaviour: methodologies and meaning

information behaviour. This article has sought to draw out the challenges associated with achieving meaningful insights into user information behaviour. These challenges do not invalidate data that has been collected and analysed, but do encourage a critical perspective on research methodologies, and the interpretation of the outcomes and findings from research projects. The design decisions made during the development of the Framework have been outlined; these reflect some common dilemmas for researchers, managers and other information and education professionals who seek to understand user: behaviour. Some researchers have avoided the dilemmas outlined in this article by focusing more narrowly on specific EIS, or upon specific learning communities. Whilst such disconnected studies offer useful isolated insights, any attempt to conduct research that can inform general policy and practice in higher education needs to be informed by an understanding of the issues associated with profiling, interpreting and changing user information behaviour.

\section{References}

Agarwal, R. and Prasad, J. (1997), 'The role of innovation characteristics and perceived voluntariness in the acceptance of information technologies', Decision Sciences, Summer (3), 557-83.

AGORA (2000), Report, available at http://www.mmu.ac.uk/h-ss/cerlim/projects/agoralhtm

Armstrong, C., Barker, A., Everitt, J., Fenton, R., Lonsdale, R., Stoker, D., Thomas, R. and Urquhart, C. (2001), 'The JISC usage surveys: trends in electronic information services (JUSTEIS) project: supply and demand in higher education', Library and Information Briefings, 106/7, 1-18.

Armstrong, C., Fenton, R. Lonsdale, R., Stoker, D., Thomas, R. and Urquhart, C. (2002), 'A study of the use of electronic information systems by higher education students in the UK', Program, 35 (3), 241-62.

Australian Bureau of Statistics (1999), Use of the Internet by Householders, Australia: ABS.

Banwell, L. and Gannon-Leary, P. (2000), 'JUBILEE: monitoring user information behaviour in the electronic age', OCLC Systems and Services, 14 (4), 189-93.

Banwell, L. and Gannon-Leary, P. (2001), 'Meaningful measures for individuals' realities: evidence form the JUBILEE project', in Proceedings of Fourth Northumbria International Conference on Libraries and Information Services, Pittsburgh, 12-16 August 2001.

Battleson, B., Booth, A. and Weinthrop, J. (2001), 'Usability testing of an academic library web site: a case study', Journal of Academic Librarianship, 27 (3), 188-98.

Bawden, D. (2001), 'Information and digital literacies: a review of concepts', Journal of Documentation, 57 (2), 218-59.

Bobbitt, L. and Dabholkar, P. (2001), 'Integrating attitudinal theories to understand and predict use of technology-based self-service: the Internet as an illustration', International Journal of Service Industry Management, 12 (5), 423-51.

Brophy, P. (2001), 'Networked learning', Journal of Documentation, 57 (1), 130-56. 
Chau, P. (2000), 'Influence of computer attitude and self-efficacy on IT usage behaviour', Journal of End User Computing, 13 (1), 26-34.

Clarke, Z. (1999), 'The EQUINOX project and the development of performance indicators for the electronic library', in Proceedings of the Third Northumbria Informational Conference on Performance Measurement in Libraries and Information Services, 27-31 August, England, 145-8.

Dalgleish, A. and Hall, R. (2000), 'Uses and perceptions of the World Wide Web in an information seeking environment', Journal of Librarianship and Information Science, 32 (3), 104-16.

Davies, C. (1998), 'User issues', in ELINOR: Electronic Library Project, British Library Research and Innovation Centre Reports, London: Bowker-Saur for the British Library, $71-85$.

Davies, P. and Cohen, S. (2001), 'The effect of the Web on undergraduate citation behaviour 1996-1999', Journal of the American Society for Information Sciences and Technology, 52 (4), 309-14.

Detlor, B. (1999), 'Leveraging the corporate library through Web user training', Library Management, 20 (7), 393-401.

De Ruyter, K., Wetzels, M. and Kleijnen, M. (2001), 'Customer adoption of e-service: an experimental study', International Journal of Service Industry Management, 12 (2), 184-208.

EDNER (2001), 'Evaluation of the Distributed National Electronic Resource (DNER)', details available at: $h t t p: / / w w w . m m u . a c . u k / h$-ss/cerlim/projects/edner.htm

Eskola, E. (1999), 'University students' information seeking behaviour in a changing learning environment: how are students' information needs, seeking and use affected by new teaching methods?', Information Research, 4, (3), available at: www.shef.ac.uk/ is/ publications/infres/isicleeskola.html

Graphic, Visualisation and Usability Centre (1999), 'Ninth WWW user survey', available at: www.gvu.gatech.edu/user_survey.

Griffiths, L., Ashworth, J., Ward, H. and Marsden, P. (1999), 'Learning online: student behaviour in a virtual campus', Virtual University Journal, 2 (4), 76-86.

Heinstrom, J. (2000), 'The impact of personality and approaches to learning on information behaviour', Information Research, 5 (3), available at: www.shef.ac.uk/ is/ publications/infres/paper $78 . h$ tml

IMPEL2 (2001) http://is.unn.ac.uk/imrilprojects/completed_research/electrnic_libraries/ impel/IMPEL2.htm

Kucuk, S. and Arslan, M. (2000), 'A cross cultural comparison of consumers' acceptance of the Web marketing facilities', Journal of Euromarketing, 9 (3), 27-44.

Lin, J. and Lu, H. (2000), 'Towards an understanding of the behavioural intention to use a web site', International Journal of Information Management, 20 (3), 197-209. 
Lubans, J. (2000), 'Study 4: Internet use (February 2000) among 3rd year students at Duke University', Durham, North Carolina, USA, available at: http://www.lib.duke.edu/lubans/ study 4 b.html

Mackie, M. and Burton, P. (1999), 'The use and effectiveness of the eLib subject gateways: a preliminary investigation', Program, 33 (4), 327-37.

Novak, D., Hoffman, T. and Yung, Y.-F. (2000), 'Measuring the customer experiences in online environments: a structural modelling approach', Marketing Science, 19 (1), 22-43.

Ozok, A. and Salvendy, G. (2000), 'Measuring consistency of Web page design and its effect on performance and satisfaction', Ergonomics, 43 (4), 23-34.

Rettie, R. (2001), 'An exploration of flow during Internet use', Internet Research, 11 (2), 103-14.

Rowley, J. (2001a), 'Encouraging and facilitating the use of EIS', in Proceedings of EUNIS 2001: The Changing Universities: The Role of Technology, Berlin, March 2001, 270-2.

Rowley, J. (2001b), 'Encouraging and facilitating the use of electronic information services (EIS)', Educational Developments, February, 12-14.

Rust, R. and Lemon, K. (2001), 'E-service and the consumer', International Journal of Electronic Commerce, 5(3), 85-101.

Saracevic, T. and Kantor, P. (1997), 'Studying the value of library and information services, Part II', Journal of the American Society for Information Science, 48 (6), 543-63.

SCONUL (1999), Information Skills in Higher Education, Task Force on Information Skills, London: SCONUL.

Urquhart, C. (forthcoming), 'Critical incident technique and explicating interviewing in studies of information behaviour', Library and Information Science Research.

Zeithaml, V., Parasuraman, A. and Malhotra, A. (2000), 'A conceptual framework for understanding e-service quality: implications for future research and managerial practice', Marketing Sciences Institute Working Paper. 